\title{
Development and Comparison of Fiber-Optic Water Temperature Sensors with Different Sized Metal Caps
}

\author{
Rinah Kim, Han Young Joo, and Joo Hyun Moon* \\ Department of Nuclear \& Energy System Engineering, Dongguk University-Gyeongju, \\ Gyeongju, Gyeongbuk 38066, Republic of Korea
}

(Received April 1, 2016; accepted March 10, 2017)

Keywords: fiber-optic temperature sensor, sensing probe, metal cap, infrared optical fiber

In this study, we developed a contact-type fiber-optic temperature sensor (CFOTS) for remote and real-time measurements of water temperature. The CFOTS consisted of a sensing probe, a transmitting infrared (IR) optical fiber, a light measuring device, and a laptop. The transmitting IR optical fiber was a polycrystalline infrared (PIR) fiber based on silver halides ( $\mathrm{AgCl}: \mathrm{AgBr})$. The light-measuring device was a thermopile-type photodiode detector module. The sensing probes were metal caps fabricated from metals of high thermal conductivity: copper and aluminum. Several metal caps of different materials and different inner diameters $(1.5,2.5$, and $3.5 \mathrm{~mm})$ were prepared and characterized to identify the optimal material and size of the sensing probe in terms of its detection performance. The CFOTS measured the water temperature of a sample in an oil bath over a range of $30-70{ }^{\circ} \mathrm{C}$. The experimental results showed that the copper metal cap with an inner diameter of $3.5 \mathrm{~mm}$ was the best water temperature sensor.

\section{Introduction}

Fiber-optic sensors (FOSs) are used in a range of fields to measure external physical properties, such as temperature, pressure, electric field, chemical concentration, and mechanical motion. ${ }^{(1)}$ The optical fiber itself works as a waveguide and a sensor. The sensing and measuring signals can be transmitted simultaneously. The FOS can make remote measurements because the signal attenuation in the optical fiber is normally small. ${ }^{(2,3)}$

A FOS can compensate for the disadvantages of commercial thermocouples and resistance temperature detectors (RTDs). A thermocouple has the advantage of a rapid response time and the ability to measure over a wide temperature range. On the other hand, the thermocouple has a disadvantage in that corrosion of the sensor can cause its performance to deteriorate. The RTD is highly linear and accurate but it is expensive, has a slow response time, and measures over a narrow temperature range. ${ }^{(4,5)}$

In a previous study, a fiber-optic temperature sensor (FOTS) was developed for remote and real-time measurements of water temperature over the range from 30 to $70{ }^{\circ} \mathrm{C} .(6,7)$ Although there is some commonality between the previous study and this study in that both used metal caps as sensing probes on the temperature sensor, there is a distinct difference in that the previous study examined the effects of a change in the outer diameter of the metal cap, whereas this study focused on the effects of a change in the inner diameter of the metal cap.

${ }^{*}$ Corresponding author: e-mail: jhmoon86@dongguk.ac.kr

http://dx.doi.org/10.18494/SAM.2017.1567 
In this study, we developed a contact-type fiber-optic temperature sensor (CFOTS) for the remote and real-time measurements of water temperature. The CFOTS consisted of a sensing probe, a transmitting infrared (IR) optical fiber, a light measuring device, and a laptop. The sensing probes were metal caps fabricated from metals with high thermal conductivity: copper and aluminum. In accordance with a previous study, a 5-mm outer diameter metal cap was selected among several different outer diameters. ${ }^{(6-8)}$ To identify the best inner diameter of the metal cap in terms of the detection performance, we fabricated and characterized several metal caps with different inner diameters while fixing the outer diameter at $5 \mathrm{~mm}$.

\section{Materials and Methods}

General silica optical fibers composed mainly of silica glass cannot detect water temperature in the range of $30-70{ }^{\circ} \mathrm{C}$. A polycrystalline infrared (PIR) fiber (PIR 900/1000, JT Ingram) based on silver halides $(\mathrm{AgCl}: \mathrm{AgBr})$ was selected to transmit the long-wavelength region. The peak wavelengths of the thermal radiation emitted from a low temperature object are in the mid-IR region. Table 1 lists the properties of the PIR fiber. The PIR fiber has a signal attenuation of 0.1-0.5 $\mathrm{dB} / \mathrm{m}$ at a wavelength of $10.6 \mu \mathrm{m} .^{(9,10)}$

The CFOTS measures the peak wavelengths emitted at a certain water temperature and derives the temperature. ${ }^{(11)}$ Wein's displacement law was applied to determine the peak wavelengths in the range of $30-70{ }^{\circ} \mathrm{C}$.

$$
\lambda_{\max } \cdot T=a
$$

In Eq. (1), $T$ is the absolute temperature in $\mathrm{K}, \lambda_{\max }$ is the peak wavelength of thermal radiation in $\mu \mathrm{m}$, and Wien's displacement constant $a$ is $2897.8 \mu \mathrm{m} \cdot \mathrm{K}$. The peak wavelengths emitted from the water were 8.44-9.56 $\mu \mathrm{m}$ according to Eq. (1).

Figure 1 presents an image and cross-sectional view of the sensing probes of the CFOTS. The sensing probes were metal caps fabricated from metals with high thermal conductivity: copper and aluminum. The thermal conductivities of copper and aluminum are 380 and $175 \mathrm{~W} / \mathrm{m} \cdot \mathrm{K}$, respectively. ${ }^{(12,13)}$ Metal caps with different inner diameters, $1.5,2.5$, and $3.5 \mathrm{~mm}$, but the same outer diameter, $5 \mathrm{~mm}$, were used. The metal caps were attached to the end of the IR optical fiber. The distance between the inner surface and the distal-end of the PIR fiber was $25 \mathrm{~mm}$.

Figure 2 presents the experimental setup to measure the water temperature in the oil bath (WHB-6, DAIHAN). The water temperature was changed by $5{ }^{\circ} \mathrm{C}$ over the range of $30-70{ }^{\circ} \mathrm{C}$. For comparison, a reference temperature was measured using a digital thermometer (A1.T9307, DAIHAN). The CFOTS was setup in contact with the water at a depth of $3.5 \mathrm{~cm}$ in the oil bath, as shown in Fig. 2.

Table 1

Properties of PIR polycrystalline fiber.

\begin{tabular}{cccccc}
\hline $\begin{array}{c}\text { Transmission } \\
\text { range }(\mu \mathrm{m})\end{array}$ & Core $(\mu \mathrm{m})$ & Cladding $(\mu \mathrm{m})$ & $\begin{array}{c}\text { Core refractive } \\
\text { index }\end{array}$ & $\begin{array}{c}\text { Numerical } \\
\text { aperture }\end{array}$ & $\begin{array}{c}\text { Operating } \\
\text { temperature }(\mathrm{K})\end{array}$ \\
\hline $4<R<18$ & $860 \pm 20$ & $1000 \pm 25$ & 2.15 & $0.30 \pm 0.03$ & $4<T<420$ \\
\hline
\end{tabular}




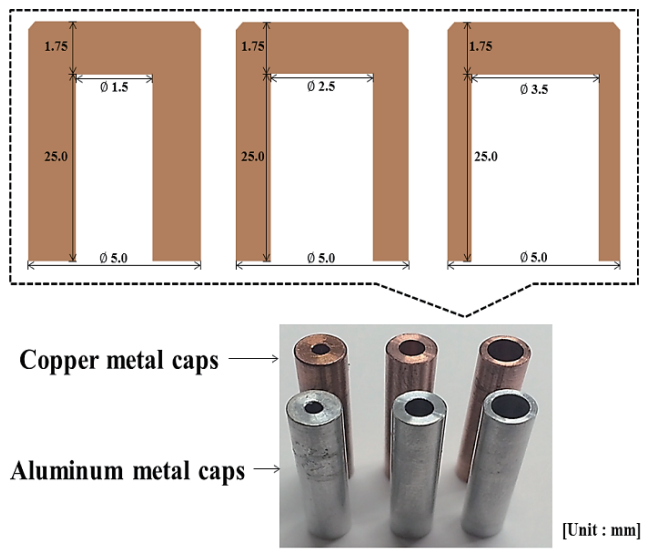

Fig. 1. (Color online) Photograph of the metal caps and cross-sectional view of the different inner diameters.

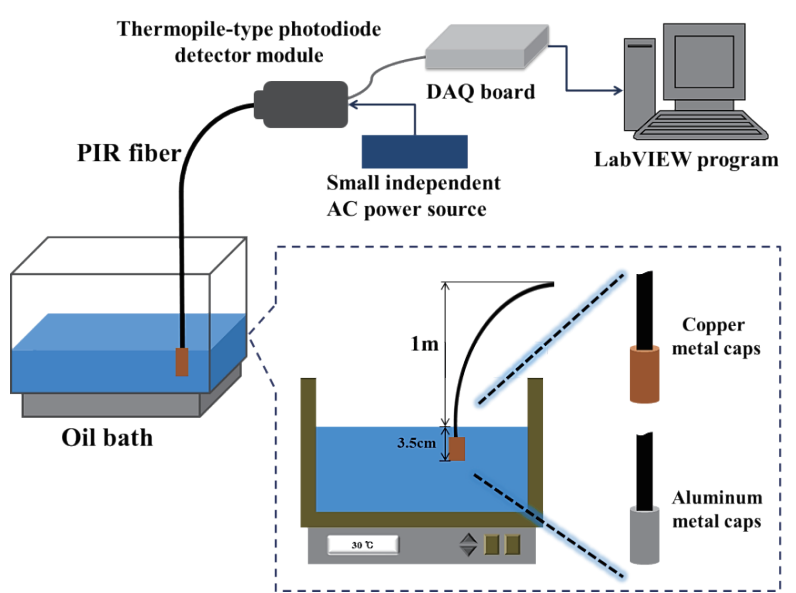

Fig. 2. (Color online) Experimental setup.

Table 2

Properties of the thermopile-type photodiode detector module.

\begin{tabular}{cccccc}
\hline Detector & $\begin{array}{c}\text { Operating } \\
\text { temperature }\left({ }^{\circ} \mathrm{C}\right)\end{array}$ & $\begin{array}{c}\text { Operating } \\
\text { wavelength range }(\mu \mathrm{m})\end{array}$ & $\begin{array}{c}\text { Responsivity } \\
(\mathrm{V} / \mathrm{W})\end{array}$ & Noise $\left(\mathrm{V} / \mathrm{Hz}^{1 / 2}\right)$ & $\begin{array}{c}\text { Bandwidth } \\
-3 \mathrm{~dB}(\mathrm{~Hz})\end{array}$ \\
\hline $\begin{array}{c}\text { 6-mm diameter } \\
\text { thermopile }\end{array}$ & 22 & $2<R<16$ & $5 \times 10^{3} / 10^{2}$ & $30 \times 10^{-6} / 10^{-7}$ & 10 \\
\hline
\end{tabular}

The IR signal emitted from the metal caps was transmitted to the thermopile-type photodiode detector module (TH-60-H, Electro-Optic System Inc.) through a PIR fiber. Table 2 lists the properties of the thermopile-type photodiode detector module. ${ }^{(14)}$ The CFOTS was powered by a small independent AC power source (PS-1, 230V, Electro-Optic System Inc.).

\section{Results and Discussion}

Figures 3 and 4 present the measurement data from the sensing probes of the CFOTSs with six different metal caps. Figure 3 shows the temperature measurements using the CFOTS with three different copper metal caps according to the different inner diameters. The correlation coefficients $\left(r^{2}\right.$ $=0.9939,0.9917$, and 0.9912 for the upper line, middle line, and lower line, respectively) confirmed the linearity of the CFOTS between the water temperature $(x)$ and output voltage $(y)$.

Figure 4 shows the temperature measurements using the CFOTS with three different aluminum metal caps. The correlation coefficients $\left(r^{2}\right)$ were $0.995,0.998$, and 0.995 for the upper line, middle line, and lower line, respectively. From the measurement data, in both cases, the $3.5 \mathrm{~mm}$ inner diameter metal caps performed better than the 1.5 and $2.5 \mathrm{~mm}$ metal caps.

Figure 5 presents the response time and reproducibility of the CFOTSs with copper and aluminum metal caps (inner diameter $3.5 \mathrm{~mm}$ and outer diameter $5 \mathrm{~mm}$ ). CFOTSs with copper metal caps showed a response time of less than $23 \mathrm{~s}$ between $10 \pm 0.5$ and $74 \pm 0.5{ }^{\circ} \mathrm{C}$ according to the experimental procedure in Ref. 11; over the same range, those with aluminum caps showed $26 \mathrm{~s}$. These tests allowed calculation of the sensing time per degree Celsius as $0.36 \mathrm{~s} /{ }^{\circ} \mathrm{C}$ for copper and 


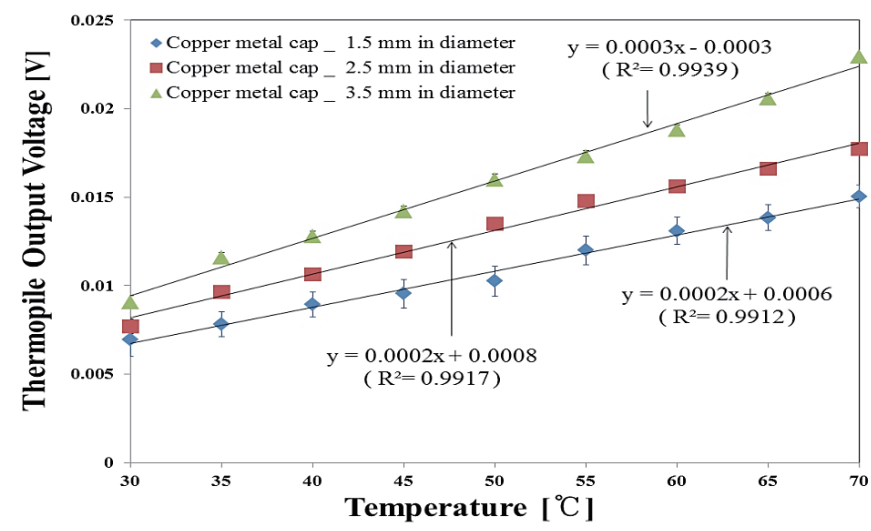

Fig. 3. (Color online) Temperature data obtained using the CFOTSs with three different copper metal caps.

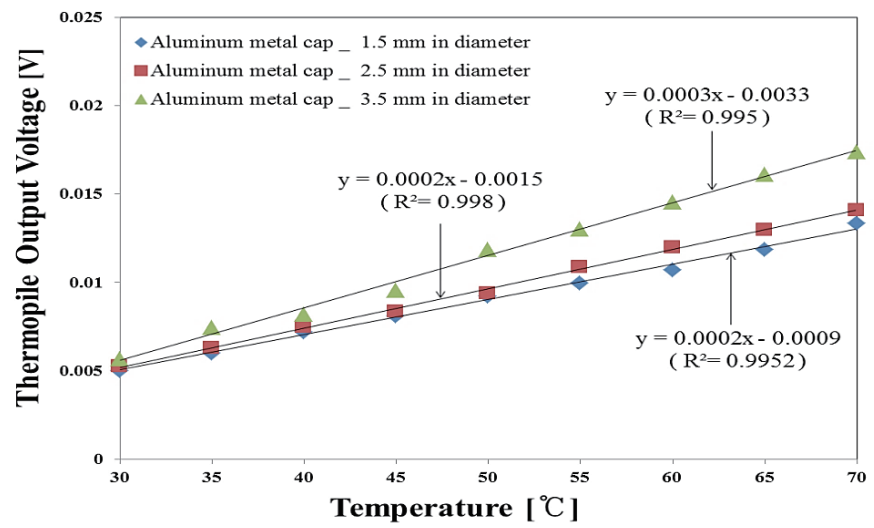

Fig. 4. (Color online) Temperature data obtained using the CFOTSs with three different aluminum metal caps.

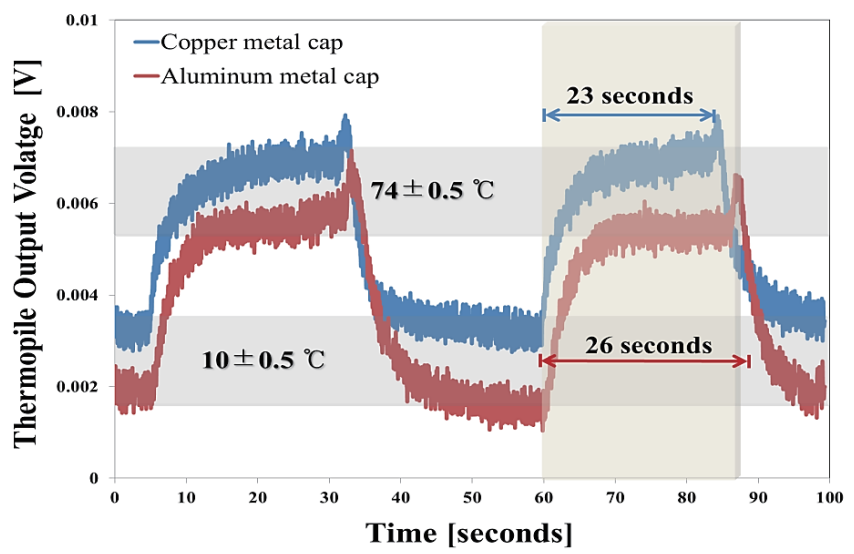

Fig. 5. (Color online) Response time of the CFOTSs with copper and aluminum metal caps.

$0.41 \mathrm{~s} /{ }^{\circ} \mathrm{C}$ for aluminum. The response time of the copper metal cap is slightly faster than that of the aluminum metal cap. Because the thermal conductivity of copper $(380 \mathrm{~W} / \mathrm{m} \cdot \mathrm{K})$ is higher than that of aluminum $(175 \mathrm{~W} / \mathrm{m} \cdot \mathrm{K})$, the heat transfer rate of copper is faster than aluminum. ${ }^{(12)}$

This study developed a CFOTS for remote and real-time measurements of water temperature; the device consisted of a sensing probe, a transmitting IR optical fiber, a light-measuring device, and a laptop. Expanding on a previous study, ${ }^{(6,7)}$ this study identified the optimal inner diameter of the metal cap of the CFOTS when its outer diameter was fixed at $5 \mathrm{~mm}$. The experimental results showed that the CFOTS developed can be used as a water temperature sensor and that the copper metal cap with an inner diameter of $3.5 \mathrm{~mm}$ and outer diameter of $5 \mathrm{~mm}$ is the best temperature sensor.

\section{Acknowledgments}

This study was supported by a National Research Foundation of Korea (NRF) grant funded by the Korean government's Ministry of Science, ICT and Future Planning (MSIP, Research Project Nos. 2012M2B2B1055499 and 2012M2A8A1027833). 


\section{References}

1 B. Lee: Opt. Fiber Technol. 9 (2003) 57.

2 S. J. Mihailov: Sensors 12 (2012) 1898.

3 A. F. Fernandez, B. Brichard, S. O'Keeffe, C. Fitzpatrick, E. Lewis, J. R. Vaille, L. Dusseau, D. A. Jackson, F. Ravotti, M. Glaser, and H. El-Rabii: Fusion Eng. Des. 38 (2008) 50.

4 H. K. Lee: Instrumentation Sensors Engineering, ed. Hyung Seolchulpansa Publishing (Hyung Seolchulpansa Publishing, Seoul, 2010) Chap. 1.

5 Y. T. Jeong: Trends in Recent Temperature Sensor, ed. Hong Rung Publishing (Hong Rung Publishing, Seoul, 2015) Chap. 2.

6 R. Kim, C. H. Park, and J. H. Moon: J. Korean Phys. Soc. 66 (2015) 1495.

7 R. Kim, C. H. Park, W. J. Yoo, and J. H. Moon: Ann. Nucl. Energy 99 (2017) 183.

8 W. J. Yoo, K. W. Jang, J. S. Moon, K. T. Han, D. J. Jeon, B.S. Lee, and B. G. Park: J. Korean Phys. Soc. 61 (2012) 1512.

9 JT Ingram Technologies Inc.: PIR fiber, http://www.jtingram.com/sitebuildercontent/sitebuilderfiles/pir.pdf (accessed May 2016).

10 W. J. Yoo, K. W. Jang, K. Seo, J. S. Moon, K. T. Han, J. Y. Park, B. G. Park, and B. S. Lee: Sensors 11 (2011) 9549.

11 E. L. Dereniak and G. D. Boreman: Infrared Detectors and Systems, ed. J. W. Goodman (John Wiley \& Sons, New York, 2004) Chap. 12.

12 P. Frank and P. David: Introduction to Heat Transfer, ed. L. Ratts (Wiley, New York, 2011) Chap. 2.

13 Y. Jeong: Infrared Sensor's Principle \& Application, ed. Inforthebooks (Inforthebooks, Seoul, 2012) Chaps. 1 and 2.

14 Electro-Optical Systems Inc.: Thermopile-Type Photodiode Detector Module, http://www.eosystems.com/ uploads/2/0/1/3/20135707/th-060-h.pdf (accessed December 2016). 